\title{
HUBUNGAN KONSELING DENGAN KEPATUHAN MINUM OBAT ANTI TUBERKULOSIS PASIEN TUBERKULOSIS DI KABUPATEN POSO
}

\author{
The Counseling Relationship with Medication Adherence Anti-Tuberculosis Medicine \\ of Tuberculosis Patients In Poso
}

\author{
Ni Nyoman Aldina ${ }^{1 *}$, Raden Bagus Bambang Hermanto ${ }^{2}$, Dafrosia Darmi Manggasa ${ }^{3}$ \\ 1. Puskesmas Kawua Kabupaten Poso \\ 2. Dinas Kesehatan Kabupaten Poso \\ 3. Poltekkes Kemenkes Palu \\ *Email korespondensi: aldinaeppink@gmail.com,
}

\begin{abstract}
ABSTRAK
Pendahuluan: Konseling terhadap penderita tuberkulosis merupakan salah satu komponen yang dapat meningkatkan kepatuhan penderita terhadap pengobatan sehingga meningkatkan angka kesembuhan. Tujuan penelitian: untuk mengetahui hubungan antara konseling pada penderita TB dengan kepatuhan minum obat anti tuberkulosis di wilayah Puskesmas Kawua dan Kayamanya Kabupaten Poso. Metode Penelitian: Desain penelitian adalah cross sectional study. Populasi adalah semua penderita tuberkulosis paru di wilayah kerja Puskesmas Kawua dan Kayamanya Kabupaten Poso. Pengambilan sampel dengan cara Purposive sampling dengan jumlah sampel 41 responden. Analisa data menggunakan Fisher 's Exact Test pada $\alpha<0,05$. Hasil: Hasil penelitian menunjukkan konseling pada penderita tuberkulosis paru baik 80,5\%, kurang $19,5 \%$. kepatuhan minum obat yaitu patuh 70,7\%, tidak patuh 29,3\%. Penderita yang mendapatkan konseling baik yang patuh minum obat $78,8 \%$ dan yang tidak patuh minum obat $21,2 \%$. Penderita yang mendapatkan konseling kurang yang patuh minum obat $37,5 \%$ dan yang tidak patuh $62,5 \%$. Hasil analisis statistik menunjukkan nilai $p=0,034$. Kesimpulan: Kesimpulan penelitian ini adalah terdapat hubungan konseling pada penderita tuberkulosis dengan kepatuhan minum obat anti tuberkulosis di wilayah Puskesmas Kawua dan Kayamanya Kabupaten Poso. Saran: Saran bagi pengelola program TB untuk mampu memberikan konseling yang berkualitas bagi penderita tuberkulosis.
\end{abstract}

Kata Kunci: konseling, kepatuhan minum obat, tuberkulosis;

\begin{abstract}
Introduction: Counseling against tuberculosis is one component that can improve patient compliance to treatment increasing the cure rate. Useful aim: The aim of this research is to determine the relationship between counseling in TB patients with medication adherence anti-tuberculosis medicine in the area of health centers in Kawua and Kayamanya Poso district. Search Methods: The design of this study was cross sectional study. The population in this study is all the patients with pulmonary tuberculosis in health centers Kawua and Kayamanya Poso district. The sample of this study was selected by applying purposive sampling with a sample of 41 respondents. The data were analyzed by using Fisher's Exact Test at $\alpha<0.05$. Results: The results showed counseling in patients with pulmonary tuberculosis $80.5 \%$ good, $19.5 \%$ less. Obedient adherence $70.7 \%$, $29.3 \%$ do not comply. Patients who receive good counseling are $78.8 \%$ adherent to take medication and $21.2 \%$ were nonadherent to take medication. Patients who receive less counseling are $37.5 \%$ adherent to take medication and $62.5 \%$ were non-adherent. Statistical analysis showed that the value of $p=0.034$. Conclusion: It is concluded that there is a relationship between counseling in tuberculosis patients with medication adherence anti-tuberculosis medicine in the area of health centers Kawua and Kayamanya Poso district. Suggestion: Suggestions for TB program managers to be able to provide quality counseling for patients with tuberculosis.
\end{abstract}

Keywords: counseling; medication adherence; tuberculosis;

https://doi.org/10.33860/mnj.v1i1.294

(C) 2020 by the authors. Submitted for possible open access publication under the terms and conditions of the Creative Commons

Attribution (CC BY SA) license (https://creativecommons.org/licenses/by-sa/4.0/). 


\section{PENDAHULUAN}

Tuberculosis (TB) adalah suatu penyakit infeksi menular yang disebabkan oleh bakteri mycobakterium tuberculosis, yang dapat menyerang berbagai organ terutama paru - paru. Penyakit ini bila tidak di obati dan pengobatannya tidak tuntas dapat menimbulkan komplikasi berbahaya hingga kematian. TB di perkirakan sudah ada sejak 5000 tahun sebelum masehi, namun kemajuan dalam penemuan dan pengendalian penyakit TB baru terjadi dalam abad terakhir. ${ }^{1}$

Dalam laporan WHO terdapat 8,6 juta kasus TB pada tahun 2012 dimana 1,1 juta orang (13\%) diantaranya adalah pasien TB dengan HIV positif. Sekitar $75 \%$ pasien TB adalah kelompok usia yang paling produktif secara ekonomis (15-50 tahun). Di perkirakan seorang pasien TB dewasa, akan kehilangan rata- rata waktu kerjanya 3 sampai 4 bulan. Hal tersebut akan berakibat pada kehilangan pendapatan tahunan rumah tangganya sekitar 20$30 \%{ }^{2}$

Indonesia merupakan salah satu Negara yang memiliki beban TB dunia. Hal ini di perkuat oleh laporan WHO pada tahun 2007 Indonesia merupakan peringkat ke tiga di dunia pada kasus $\mathrm{TB}$, kemudian jumlah kasus menurun pada tahun 2009 sehingga menjadi peringkat kelima dunia. Pada tahun 2012 Indonesia menjadi naik ke peringkat empat dengan jumlah kasus TB di dunia. ${ }^{2}$

Di Indonesia Tahun 2014 ditemukan kasus baru BTA Positif sebanyak 176.667 kasus, menurun bila dibandingkan dengan kasus baru BTA positif yang ditemukan pada tahun 2013 yang sebesar 196.310 kasus. Untuk Angka Keberhasilan pengobatan di Indonesia yaitu sebesar 81,3\% masih rendah dari target Renstra Kementerian Kesehatan RI sebesar $88 \%$. Angka keberhasilan pengobatan TB di antar provinsi di Indonesia yaitu angka terendah terdapat di provinsi papua ( $24 \%$ ) dan angka keberhasilan pengobatan tertinggi yaitu provinsi Gorontalo ( $96 \%$ ). ${ }^{3}$

Penemuan kasus baru BTA Positif di Propinsi Sulawesi Tengah tahun 2014 jumlah Kasus Baru BTA Positif yaitu 3.848 kasus. Untuk angka kesembuhan dan keberhasilan pengobatan TB BTA positif tahun 2014 propinsi Sulawesi Tengah masih belum memenuhi target yaitu $86 \%$ masih rendah dari target Kementerian Kesehatan RI sebesar $88 \%$. $^{4}$

Penemuan kasus baru BTA Positif di Kabupaten Poso tahun 2014 yaitu 154 kasus sedangkan pada tahun 2015 jumlah kasus baru TB 143 kasus. Untuk angka kesembuhan dan keberhasilan pengobatan TB BTA positif Kabupaten Poso masih belum memenuhi target yaitu 58,53\% masih rendah dari nasonal yaitu Kementerian Kesehatan RI sebesar 88 \%. ${ }^{5}$ Di Puskesmas Kawua dan Puskesmas Kayamanya, Penemuan kasus baru TB paru tahun 2015 sebanyak 44 kasus yang terdiri atas Puskesmas Kawua 23 kasus dan Puskesmas Kayamanya 21 kasus, meningkat dibandingkan dengan tahun sebelumnya (tahun 2014) dimana puskesmas Kawua dan Kayamanya jumlah kasusnya terdapat 31 kasus.

Walaupun penyakit TB dapat disembuhkan dengan obat anti TB, penanggulangan dan pemberantasannya sampai saat ini belum memuaskan. Angka drop out (mangkir, tidak patuh berobat) yang tinggi, pengobatan tidak adekuat, dan resistensi terhadap Obat Anti Tuberculosis (OAT) yaitu MDR TB merupakan kendala utama yang sering terjadi dalam pengendalian $\mathrm{TB}$ dan merupakan tantangan terhadap program pengendalian TB. ${ }^{6}$

Pengobatan yang tidak teratur dapat menyebabkan kuman menjadi resistensi terhadap OAT, memerlukan pengobatan yang sangat lama dengan tingkat keberhasilan yang masih rendah. Kegagalan pada pengobatan TB dengan reisitensi akan menyebabkan rantai penularan kuman yang telah resistensi terus meluas dan meningkatkan resiko terjadi resistensi terus meluas dan meningkatkan resiko terjadinya resistensi primer. ${ }^{7}$

Konseling merupakan suatu proses pemberian bantuan kepada klien untuk mengatasi masalahnya, ${ }^{8}$ konseling dalam penanganan tuberkulosis diharapkan mampu meningkatkan kepatuhan penderita dalam pengobatan sehingga meningkatkan angka kesembuhan.

Konseling penting dilakukan bagi penderita TB selain untuk mengupayakan agar rutin kontrol dan teratur minum obat juga agar penderita mampu mengerti bagaimana mengupayakan kesembuhan sempurna bagi dirinya. Pada penelitian yang dilakukan oleh Loriana dkk (2014) membuktikan adanya perbedaan yang bermakna antara tingkat kepatuhan berobat pada penderita TB Paru sebelum dan sesudah mendapat konseling. ${ }^{9}$

Jumlah penderita TB paru pada 2 wilayah kerja Puskesmas di Kabupaten Poso yaitu Kawua dan Kayamanya yaitu 44 kasus. Dalam penanganan penderita TB paru ditemukan permasalahan dalam pengobatan seperti beberapa pasien terkadang pasien 
terlambat mengambil obat serta tidak kontrol pengobatan tepat waktu sehingga penulis tertarik untuk melakukan penelitian mengenai hubungan konseling TB dengan kepatuhan minum obat TB pada penderita TB di puskesmas Kawua dan Puskesmas Kayamanya Kabupaten Poso.

\section{METODE PENELITIAN}

Jenis penelitian ini adalah penelitian kuantitatif dengan desain adalah cross sectional study. Populasi dalam penelitian ini adalah semua penderita tuberkulosis di Kabupaten Poso pada 2 wilayah kerja Puskesmas yaitu Puskesmas Kawua dan Kayamanya yang berjumlah 44 orang. Pengambilan sampel dengan metode purposive sampling dengan kriteria inklusi yaitu: 1) pasien TB yang bersedia menjadi responden, 2) pasien TB yang memiliki kartu TB 01. Kriteria ekslusi yaitu: 1) penderita TB anak usia Balita, 2) penderita yang tidak berada ditempat pada saat penelitian. Penelitian di lakukan pada tahun 2016 dengan mengunjungi pasien tuberkulosis, menilai kualitas konseling yang diterima oleh pasien, kepatuhan minum obat melalui pengisian kuesioner dan mengidentifikasi kartu pengobatan TB.

\section{HASIL PENELITIAN}

Tabel 1. Karakteristik Responden di Wilayah Kerja Puskesmas Kawua dan Kayamanya

\begin{tabular}{lcc}
\hline Karakteristik & F & \% \\
\hline Umur & & \\
$\leq 20$ tahun & 4 & 9,8 \\
$21-30$ tahun & 9 & 22,0 \\
$31-40$ tahun & 9 & 22,0 \\
$41-50$ tahun & 8 & 19,5 \\
$51-60$ tahun & 7 & 17,1 \\
$\geq 60$ tahun & 4 & 9,8 \\
Jenis Kelamin & & \\
Laki-laki & 23 & 56,1 \\
Perempuan & 18 & 43,9 \\
Pendidikan & & \\
SD & 7 & 17,1 \\
SMP & 12 & 29,3 \\
SMA & 18 & 43,9 \\
Perguruan Tinggi & 4 & 9,8 \\
Pekerjaan & & \\
PNS & 5 & 12,2 \\
Swasta & 14 & 34,1 \\
Petani & 5 & 12,2 \\
Ibu Rumah Tangga & 14 & 34,1 \\
Pelajar/Mahasiswi & 3 & 7,3
\end{tabular}

\begin{tabular}{lcc}
\hline Karakteristik & F & \% \\
\hline $\begin{array}{l}\text { Status Pernikahan } \\
\text { Menikah }\end{array}$ & 29 & 70,7 \\
Belum & & \\
Menikah & 10 & 24,4 \\
Janda/Duda & 2 & 4,9 \\
\hline Jumlah & $\mathbf{4 1}$ & $\mathbf{1 0 0}$ \\
\hline
\end{tabular}

Berdasarkan tabel 1 menunjukkan bahwa karakteristik responden berdasarkan umur yang terbanyak adalah umur 21-30 tahun dan 31-40 tahun masing - masing yaitu 9 responden $(22,0 \%)$ dan yang terendah adalah umur $\leq 20$ tahun dan $\geq 60$ tahun masing - masing yaitu 4 responden $(9,8 \%)$. Jenis kelamin terbanyak adalah laki-laki yaitu 23 responden $(56,1 \%)$ dan perempuan sebanyak 18 responden (43,9\%). Pendidikan terbanyak adalah SMA yaitu 18 responden $(43,9 \%)$ dan jumlah terendah adalah Perguruan Tinggi yaitu 4 responden $(9,8 \%)$. Pekerjaan terbanyak adalah swasta dan ibu Rumah Tangga masing - masing yaitu 14 responden $(34,1 \%)$ dan jumlah terendah adalah Pelajar/Mahasiswa yaitu 3 responden (7,3\%). Status Pernikahan terbanyak adalah menikah yaitu 29 responden $(70,7 \%)$ dan jumlah terendah adalah Janda/Duda yaitu 2 responden $(4,9 \%)$.

Tabel 2. Status dan Kategori Pengobatan Responden di Wilayah Kerja Puskesmas Kawua dan Kayamanya

\begin{tabular}{lcc}
\hline Variabel & $F$ & $\%$ \\
\hline Status Pengobatan & & \\
Tahap Lanjutan & 33 & 80,5 \\
Tahap Intensif & 8 & 19,5 \\
\hline Jumlah & $\mathbf{4 1}$ & $\mathbf{1 0 0}$ \\
\hline Kategori Pengobatan & & \\
Kategori I & 39 & 95,1 \\
Kategori II & 2 & 4,9 \\
\hline Jumlah & $\mathbf{4 1}$ & $\mathbf{1 0 0}$ \\
\hline
\end{tabular}

Berdasarkan tabel 2 menunjukkan status pengobatan penderita terbanyak adalah pada tahap lanjutan yaitu 33 responden $(80,5 \%)$ dan jumlah terendah adalah tahap intensif yaitu 8 responden $(19,5 \%)$. Kategori pengobatan terbanyak adalah 
kategori I yaitu 39 responden $(95,1)$ dan terendah adalah kategori II yaitu 2 responden $(4,9 \%)$.

Tabel 3 Distribusi Responden Berdasarkan Konseling di Wilayah Kerja Puskesmas Kawua dan Kayamanya

\begin{tabular}{lccc}
\hline \multicolumn{1}{r}{ Konseling } & F & \% \\
\hline Baik & 33 & 80,5 \\
Kurang & 8 & 19,5 \\
\hline \multicolumn{2}{c}{ Jumlah } & $\mathbf{4 1}$ & $\mathbf{1 0 0}$ \\
\hline
\end{tabular}

Berdasarkan tabel 3 menunjukkan bahwa responden yang mendapatkan konseling baik sebanyak 33 responden $(80,5 \%)$ dan konseling kurang sebanyak 8 responden $(19,5 \%)$.

Tabel 4. Distribusi Responden Berdasarkan Kepatuhan Minum Obat di Wilayah Kerja Puskesmas Kawua dan Kayamanya Kabupaten Poso

\begin{tabular}{lcc}
\hline Kepatuhan Minum Obat & F & \% \\
\hline Patuh & 29 & 70,7 \\
Tidak patuh & 12 & 29,3 \\
\hline \multicolumn{1}{c}{ Jumlah } & $\mathbf{4 1}$ & $\mathbf{1 0 0}$ \\
\hline
\end{tabular}

Berdasarkan tabel 4 menunjukkan bahwa responden yang patuh minum obat sebanyak 29 responden $(70,7 \%)$, dan yang tidak patuh sebanyak 12 responden $(29,3 \%)$.

Tabel 5. Hubungan Konseling Dengan Kepatuhan Minum Obat Pasien Tuberkulosis Paru di Wilayah Kerja Puskesmas Kawua dan Puskesmas Kayamanya Kabupaten Poso

\begin{tabular}{|c|c|c|c|c|c|c|c|}
\hline \multirow{3}{*}{ Konseling } & \multicolumn{4}{|c|}{ Kepatuhan } & \multicolumn{2}{|c|}{ Total } & \multirow{3}{*}{$P$} \\
\hline & \multicolumn{2}{|c|}{ Patuh } & \multicolumn{2}{|c|}{$\begin{array}{l}\text { Tidak } \\
\text { patuh }\end{array}$} & \multirow[b]{2}{*}{$\mathrm{n}$} & \multirow[b]{2}{*}{$\%$} & \\
\hline & $\mathrm{n}$ & $\%$ & & $\%$ & & & \\
\hline Baik & 26 & 63,4 & 7 & 17,1 & 33 & 80,5 & \\
\hline Kurang & 3 & 7,3 & 5 & 12,2 & 8 & 19,5 & 0,034 \\
\hline Jumlah & 29 & 70,7 & 12 & 29,3 & 41 & 100 & \\
\hline
\end{tabular}

Berdasarkan tabel 5 menunjukkan bahwa dari 33 responden yang mendapatkan konseling dengan baik terdapat 26 responden $(78,8 \%)$ yang patuh minum obat dan 7 responden $(21,2 \%)$ yang tidak patuh minum obat. Dari 8 responden yang mendapatkan konseling yang kurang terdapat 3 responden $(37,5 \%)$ yang patuh minum obat dan 5 responden $(62,5 \%)$ yang tidak patuh minum obat.

Hasil analisis uji statistik dengan Fisher's Exact Test menunjukkan nilai $P=0,034 \quad(<0,05)$ sehingga Ha diterima, hal ini menunjukkan terdapat hubungan antara pemberian konseling dengan kepatuhan minum obat pasien tuberkulosis di wilayah kerja Puskesmas Kawua dan Puskesmas Kayamanya Kabupaten Poso.

\section{PEMBAHASAN}

Hasil penelitian ini membuktikan bahwa sebagian besar repsonden yang mendapatkan konseling dengan baik patuh dalam pengobatan TB. Hal ini berarti bahwa penderita dengan konseling baik cenderung patuh dalam pengobatan TB .

Pemberian konseling dapat mewujudkan peningkatan pengetahuan, sikap positif dan kepatuhan berobat penderita TB paru. Konseling kesehatan yang diberikan secara terstruktur mempunyai efek lebih baik sehingga panduan yang diberikan dapat dibaca kembali oleh pasien dan keluarga. Kebutuhan informasi pada pasien yang menjalankan pengobatan Tuberkulosis sangat tinggi. ${ }^{10}$ Adapun informasi yang dibutuhkan antara lain tentang implikasi kesehatan mereka, bagaimana meningkatkan kepedulian terhadap faktor resiko dan upaya pencegahan. Pasien yang menjalani pengobatan tuberkulosis membutuhkan informasi atau konseling kesehatan tentang perawatan dan pengobatan Tuberkulosis. ${ }^{10}$

Penelitian ini juga menunjukkan terdapat responden yang mendapatkan konseling baik namun tidak patuh minum obat. Beberapa penyebab ketidakpatuhan pasien minum obat antara lain tidak diawasi oleh Pengawas Menelan Obat (PMO), pasien tidak melakukan kontrol pengobatan sesuai dengan jadwal yang ditentukan dan pasien tidak mengambil obat tepat waktu sesuai dengan jadwal. ${ }^{9}$

Penelitian membuktikan bahwa pengaruh konseling oleh tenaga kesehatan terhadap penderita TBC di New York sangat besar hasilnya terhadap kepatuhan. Hasil penelitian ini juga sesuai dengan penelitian yang dilakukan oleh Husnawati, dkk (2007) bahwa terdapat pengaruh konseling tentang terapi 
obat terhadap tingkat kepatuhan penderita TBC paru pada terapi obat. ${ }^{11}$

Pada penelitian ini ditemukan adanya pasien yang memiliki konseling kurang baik namun patuh minum obat TB, hal ini disebabkan karena adanya dukungan keluarga dalam pengobatan pasien serta adanya PMO. Hasil penelitian Hutapea (2011), membuktikan bahwa dukungan keluarga dapat meningkatkan kepatuhan minum OAT penderita TB Paru. ${ }^{12}$

Kepatuhan pengobatan TB merupakan hal yang sangat penting, karena bila pengobatan tidak dilakukan secara teratur dan tidak sesuai dengan waktu yang telah ditentukan maka akan dapat timbul kekebalan kuman TB terhadap Obat Anti Tuberculosis (OAT) secara meluas atau disebut Multi Drugs Resistance (MDR) (Depkes RI, 2008).

Konseling TB merupakan suatu proses komunikasi dua arah antara konselor dengan penderita untuk membantu klien mengetahui dan memahami kepatuhan minum obat anti TB (OAT) dengan strategi Direct Observed Treatment Short Course (DOTS) berdasarkan Standar Internasional Penanganan Tuberkulosis (International Standart for Tuberculosis Care/ ISTC). ${ }^{7}$

\section{SIMPULAN DAN SARAN}

Berdasarkan hasil penelitian tentang hubungan konseling dengan kepatuhan minum obat penderita tuberkulosis paru di wilayah kerja Puskesmas Kawua dan Puskesmas Kayamanya Kabupaten Poso dapat disimpulkan bahwa konseling terhadap penderita tentang pengobatan tuberkulosis sebagian besar baik yaitu 33 Responden (80,5\%), kepatuhan minum obat penderita tuberkulosis sebagian besar patuh yaitu 29 Responden $(70,7 \%)$ dan terdapat hubungan antara konseling dengan kepatuhan minum obat pasien tuberkulosis paru di wilayah kerja Puskesmas Puskesmas Kawua dan Puskesmas Kayamanya Kabupaten Poso. Saran terhadap pengelola program TB untuk mampu memberikan konseling yang berkualitas bagi penderita tuberkulosis sehingga pasien patuh terhadap pengobatan untuk meningkatkan kesembuhan dan mencegah resisten terhadap obat OAT.

\section{DAFTAR PUSTAKA}

1. Kamso PS, Manaf A, Alamiahnya R, Tuberkulosis UP, Tuberkulosis $\mathrm{P}$, Mutu P, et al. Pedoman Nasional Penanggulangan
Tuberkulosis edisi 2 [Internet]. Kementerian Kesehatan RI. 2011 [cited 2016 Jul 24]. p. 13-4. Available from: https://med.unhas.ac.id/farmakologi/wpcontent/uploads/2014/10/Pedoman-NasionalPenanggulangn-TB-2011.pdf

2. Dirjen P2\&PL Kementerian Kesehatan RI. Terobosan Menuju Akses Universal, Strategi Nasional Pengendalian TB di Indonesia 20102014. Stop TB [Internet]. 2011;1-80. Available from:

http://www.searo.who.int/indonesia/topics/tb/str anas_tb-2010-2014.pdf

3. Kementrian Kesehatan Republik Indonesia. Profil Kesehatan Indonesia 2015 [Internet]. Kementerian Kesehatan Republik Indonesia. 2015. Available from: https://www.kemkes.go.id/resources/download/ pusdatin/profil-kesehatan-indonesia/profilkesehatan-Indonesia-2015.pdf

4. Dinas Kesehatan Sulawesi Tengah. Profil Kesehatan Propinsi Sulawesi Tengah. Palu; 2014.

5. Dinas Kesehatan Kabupaten Poso. Pofil Kesehatan Kabupaten Poso. Poso; 2014.

6. Bagiada IM, Primasari NLP. Faktor-Faktor Yang Mempengaruhi Tingkat Ketidakpatuhan Penderita Tuberkulosis Dalam Berobat Di Poliklinik Dots Rsup Sanglah Denpasar. J Penyakit Dalam. 2010;11(3):158-63.

7. $\mathrm{CDC} \mathrm{C}$ for disease control and prevention. $\mathrm{TB}$ Elimination: Extensively Drug-Resistant Tuberculosis (XDR-TB). New Lett [Internet]. 2013;1-3. Available from: http://www.cdc.gov/tb/publications/factsheets/dr tb/xdrtb.htm

8. Gunarsa S. Konseling, dan Psikoterapi. Jakarta: PT BPK Gunung Mulia; 2007.

9. Loriana R, Parellangi, Siswoyo. Efek konseling terhadap pengetahuan, sikap dan kepatuhan berobat penderita tuberkulosis paru. J Husada Mahakam. 2013;III(6):281-7.

10. Pasek MS, Suryani N, K PM. Hubungan Persepsi Dan Tingkat Pengetahuan Penderita Tuberkulosis Dengan Kepatuhan Pengobatan Di Wilayah Kerja Puskesmas Buleleng 1. J Magister Kedokt Kel [Internet]. 2013;1(1):14-23. Available from: https://media.neliti.com/media/publications/134 94-ID-hubungan-persepsi-dan-tingkat- 
pengetahuan-penderita-tuberkulosis-dengankepatuha.pdf

11. Harianto, Husnawati, Retnosari. Pengaruh Konseling Tentang Terapi Obat Tbc Terhadap Kepatuhan Penderita Tbc Paru Pada Terapi Obat Periode Februari-Mei 2007 Di Kelurahan Pancoran Mas-Depok. Maj Ilmu Kefarmasian [Internet]. 2007;IV(2):49-58. Available from: http://journal.ui.ac.id/index.php/mik/article/view
$/ 1187$

12. Hutapea TP. Pengaruh Dukungan Keluarga Terhadap Kepatuhan Minum Obat Anti Tuberkulosis, RSUD dr. Saiful Anwar, Malang [Internet]. 2016 [cited 2016 Jun 24]. p. 1-66. Available from: http://arsip.jurnalrespirologi.org/jurnal/April09/ Dukungan Keluarga.pdf 